Original Research Article

\title{
Evaluation of analgesic and anti-inflammatory activity of a combination of tramadol-pregabalin in animal models of pain and inflammation
}

\author{
Suthakaran C.*, Raja T. A. R., Kayalvizhi M. K., Nithya K., Ramnarayana Reddy R. V.
}

Department of Pharmacology, Melmaruvathur Adhi Parasakthi Institute of Medical Sciences and Research, (Affiliated to The Tamilnadu Dr. MGR Medical University) Melmaruvathur, 603319 Kancheepuram, Tamilnadu, India

Received: 10 April 2017 Accepted: 02 May 2017

*Correspondence to:

Dr. Suthakaran C.,

Email: drcsudha@gmail.com

Copyright: (C) the author(s), publisher and licensee Medip Academy. This is an openaccess article distributed under the terms of the Creative Commons Attribution NonCommercial License, which permits unrestricted noncommercial use, distribution, and reproduction in any medium, provided the original work is properly cited.

\begin{abstract}
Background: A major goal of pain management is to provide pain relief that is clinically meaningful, sustained, and associated with minimum and reversible adverse effects. Since single analgesic drug is not effective in all patients, there is a need either to develop new and more effective drugs or to identify favourable combinations of drugs that are already available. The aim of the present was to evaluate the analgesic and anti-inflammatory activity of tramadol and pregabalin when used alone or in combination in animal models of pain and inflammation.
\end{abstract}

Methods: The animals (rats and mice) were divided into eight groups with six animals in each group. Analgesia was assessed by acetic acid induced writhing and tail flick methods in mice and hot plate method in rats. Paw oedema model in rats after induction with $0.1 \mathrm{ml}$ of $1 \%$ carrageenan was used to assess the anti-inflammatory activity. The percentage inhibition of writhes and prolongation of reaction time were used for assessing analgesic activity and reduction in paw volume was used for assessing anti-inflammatory activity. The results obtained were analysed by ANOVA and Tukey HSD Post-hoc Test.

Results: Treatment with tramadol pregabalin alone or in combination reduced writhing episodes significantly in acetic acid induced writhing in mice as compared to control indicating its analgesic effect and the highest percentage inhibition of pain was seen with high dose tramadol plus pregabalin. Treatment in Hot plate and Tail flick methods significantly prolonged the reaction time at all time points.

Conclusions: Tramadol when combined with pregabalin may enhance its antinociceptive effects. If confirmed in additional models of acute and/or chronic pain this combination might be useful in the clinical management of pain not associated with inflammation.

Keywords: Combination analgesia, Pain, Pregabalin, Tramadol

\section{INTRODUCTION}

Pain is an unpleasant experience and the mechanisms involved in its production transmission or perception has been one of the most intensely investigated areas in biomedical science over several decades. Pain not only places an enormous burden on the patients as it costs several billion dollars in medical expenditures as well as on lost productivity, it poses a formidable challenge for the clinicians as well. Why pain continues to be a problem for clinicians is that pain does not conform to the scientific approach to health and disease, it is subjective rather than objective and the causal basis is often poorly understood. In addition to providing relief, the objective of proper treatment of pain is to prevent or attenuate both peripheral and central sensitization that increases pain. ${ }^{1-3}$ Although an array of agents are available for the management of pain, the optimal treatment for pain remains largely elusive and an update on relative efficacy of oral analgesics indicated that no single drug is effective in all patients and that even the best drugs failed to provide good levels of pain relief in at least $30 \% .^{4}$ 
Pregabalin, a structural analogue of the inhibitory neurotransmitter $\gamma$-aminobutyric acid, by binding to the a2-d subunit of voltage-gated calcium channels in the nervous system reduces the release of several excitatory neurotransmitters in particular the excitatory amino acid glutamate blocks the development of hyperalgesia and central sensitization. ${ }^{5-7}$ It demonstrated antiallodynic and antihyperalgesic activities in various rodent models of pain and perioperative administration of pregabalin was associated with a significant decrease in pain score after surgery. ${ }^{8,9}$ Preclinical and clinical data suggest that pregabalin may be effective in the treatment of nociceptive inflammatory pain and hence pregabalin has emerged as an attractive adjuvant in combination with opioids for the management of acute pain.

Tramadol, a synthetic, centrally acting analgesic agent with two distinct, synergistic mechanisms of action, has of late emerged as an alternate to opioids in the management of acute pain. ${ }^{10}$ When used in combination with paracetamol or NSAIDs, it has been shown to enhance the analgesic efficacy in a complementary manner and improve the tolerability profile. ${ }^{11-13}$

A major goal of pain management is to provide pain relief that is clinically meaningful, sustained, and associated with minimum and reversible adverse effects. Since single analgesic drug is not effective in all patients, there is a need either to develop new and more effective drugs or to identify favourable combinations of drugs that are already available. Although combinations offer the possibility of several desirable outcomes, the combinations must be rigorously tested before being introduced into clinical practice. ${ }^{14}$ Hence, the aim of the present study was to evaluate the analgesic and antiinflammatory activity of tramadol and pregabalin when used alone or in combination in animal models of pain and inflammation.

\section{METHODS}

The entire study was carried out using male adult Wistar rats, (weighing 180 to $230 \mathrm{~g}$ ) and Swiss albino mice (weighing 25 to $30 \mathrm{~g}$ ) between $09.00 \mathrm{a} . \mathrm{m}$. and $2.00 \mathrm{p} . \mathrm{m}$. The animals were kept in a separate temperatureregulated room in cages with air-cooling and 12 hour light and dark cycle. They had free access to water and standard laboratory diet. All experiments were conducted on separate groups of animals and each animal was used only once and only in a single test to avoid interference between tests. Rats and mice were divided into groups with 6 members in each group. Control groups (Group I) were administered normal saline at the dose of $10 \mathrm{ml} / \mathrm{kg}$ and diclofenac 100mg/kg (Group II). Tramadol was administered at dosage of 4 (Group III) or 8 (Group IV) $\mathrm{mg} / \mathrm{kg}$ and the dosage for pregabalin was 6 (Group V) 12 (Group VI) $\mathrm{mg} / \mathrm{kg}$ while the dosage for combination of pregabalin and tramadol was $6 / 4 \mathrm{mg} / \mathrm{kg}$ (Group VII) and $12 / 8 \mathrm{mg} / \mathrm{kg}$ (Group VIII). The combination ratio of pregabalin and tramadol was determined considering the maximum recommended human dose of pregabalin and tramadol, respectively. Diclofenac is often used as reference drug to compare other analgesic drugs in inflammatory pain. All the drugs were administered through oral route after dissolving them in normal saline. All chemicals and solvents (Pregabalin, Tramadol Hydrochloride, $\lambda$-carrageenan and Saline) used were at least of analytical grade and were obtained commercially.

\section{Acetic acid-induced abdominal writhing in mice}

The analgesic activity was evaluated in mice by injecting $0.6 \%$ acetic acid $(10 \mathrm{~mL} / \mathrm{kg})$ intraperitoneally (ip) into the lower right quadrant of the abdominal cavity at an angle of $30^{\circ}$ and a depth of $5 \mathrm{~mm} .{ }^{15}$ The test drugs were administered orally to the mice 30 minutes before acetic acid injection. Immediately after injection, the mice were observed for writhing reflex, which is characterized by abdominal muscle contractions associated with inward outstretching of the hind limbs, a hind paw reflex, or whole body extension. The number of writhing reflexes, were observed over a period of twenty min. Analgesic effect was quantified as the percent reduction in the number of writhes produced by each drug dose. For a given dose, percentage inhibition was calculated using the following formula: \% inhibition $=[(\mathrm{Wc}-\mathrm{Wt}) \times 100] /$ $\mathrm{Wc}$ where, $\mathrm{Wc}=$ No. of writhes in control group, $\mathrm{Wt}=$ No. of writhes in test group.

\section{Tail-immersion test}

Mice were placed into individual restraining cages leaving the tail hanging out freely. The animals were allowed to adapt to the cages for $30 \mathrm{~min}$ before testing. The lower $5 \mathrm{~cm}$ portion of the tail was marked. This part of the tail was immersed in a cup of freshly filled water of exactly $55^{\circ} \mathrm{C}$. The reaction time was recorded with the help of a stopwatch. After each determination, the tail was carefully dried. The reaction time was determined before $(0 \mathrm{~h})$ and thereafter at 1 and $2 \mathrm{~h}$ following oral administration of the test substances. The cut off time of the immersion was 15 seconds. Tail immersion latency was measured as the time between tail immersion and tail withdrawal. ${ }^{16}$ Change in tail immersion latency, Dt (s), was calculated for each animal according to the formula [Dt (s) =post drug latency - pre drug latency $].{ }^{17}$ For each animal, the \% maximum possible effect (\%MPE) was calculated using the following formula: [(Post drug latency-Pre drug latency) / (15-Pre drug latency)] X100.

\section{Hot Plate Method}

The analgesic activity was also assessed using hot plate method of Eddy and Leimbach in rats. ${ }^{18}$ In this experiment, the hot-plate apparatus was maintained at $55 \pm 0.1^{\circ} \mathrm{C}$. Rats were placed in an acrylic cylinder $(20 \mathrm{~cm}$ in diameter) on the heated surface, and the time between placement and licking of their hind paws or jumping was recorded as the response latency. A $20 \mathrm{~s}$ cut-off was used to prevent tissue damage. The response latency was 
recorded before ( $0 \mathrm{~min}$ ) and 1/2,1, 11/2 and $2 \mathrm{~h}$ following oral administration of drugs. Analgesia was defined as prolongation of latency without licking or flicking of hind limb or jumping. Animals presenting with latencies higher than $20 \mathrm{~s}$ at $0 \mathrm{~min}$ were excluded. For each animal, the $\%$ maximum possible effect (\%MPE) was calculated using the following formula: [(Post drug latency-Pre drug latency)/ (20-Pre drug latency)] X100.

\section{Anti-inflammatory activity [Carrageenan (CARR) induced paw oedema]}

We followed the method adopted by Winter et al subsequently modified by Singh and Ghosh for evaluating the acute anti-inflammatory activity in rats. ${ }^{19,20}$ Paw oedema was induced in the right hind paw of each rat by intraplantar injection of $100 \mu$ l of $1 \%$ (suspension in saline) lambda carrageenan. The paw volume of rats was measured by plethysmometer, before the injection of carrageen, $2.5 \mathrm{~h}$ after the injection of carrageen (just before the administration of the test drugs and then again 1 and $2 \mathrm{~h}$ after test drug administration. The degree of oedema induced was assessed by the volume of the right hind paw before and after carrageenan treatment, respectively. Mean baseline paw volume ranged from 1.3 to $1.4 \mathrm{ml}$ among the different treatment groups. When measured $2.5 \mathrm{~h}$ after the injection of carrageenan, mean paw volume ranged from 2.4 to $2.7 \mathrm{ml}$ among the different treatment groups. Drug effects were expressed as a difference score in which the paw volume measured $2 \mathrm{~h}$ after administration of the drug was subtracted from that determined immediately before (i.e., $2.5 \mathrm{~h}$ after carrageenan). Negative values, therefore, represent a reduction in inflammation.

\section{Statistical analysis}

The data were expressed as mean \pm SD (standard deviation). All data were subjected to Analysis of variance (ANOVA) and individual comparisons were made using Tukey HSD Post-hoc Test. The differences were considered significant if $\mathrm{p}<0.05$.

\section{RESULTS}

The effect of the drugs on the acetic acid- induced abdominal constrictions and percent reduction in mice is presented in Table 1. The results showed that there were statistically significant differences between group means as determined by one-way ANOVA and there was a significant dose dependent decrease in the number of writhes in all the treated groups as compared to the control group.

Table 1: Effect of tramadol or pregabalin alone or in combination on acetic acid induced writhing in mice.

\begin{tabular}{|c|c|c|c|c|}
\hline Group & Drug & $\begin{array}{l}\text { Dose } \\
\mathrm{mg} / / \mathrm{kg}\end{array}$ & $\begin{array}{l}\text { No of } \\
\text { writhing } \\
\text { Mean } \pm \text { SD }\end{array}$ & $\begin{array}{l}\% \\
\text { Inhibition } \\
\text { Mean } \pm \text { SD }\end{array}$ \\
\hline I & Saline & $10 \mathrm{~mL} / \mathrm{kg}$ & $35.8 \pm 2.6$ & \\
\hline II & Diclofenac & 100 & $11.2 \pm 2.5 * * *$ & $68.4 \pm 8.5$ \\
\hline III & Tramadol & 4 & $16.8 \pm 2.6 * * *$ & $53.1 \pm 5.9$ \\
\hline IV & Tramadol & 8 & $23.0 \pm 2.8 * * *$ & $35.8 \pm 6.3$ \\
\hline $\mathrm{V}$ & Pregabalin & 6 & $14.5 \pm 2.6^{* * *}$ & $59.4 \pm 7.7$ \\
\hline VI & Pregabalin & 12 & $18.2 \pm 4.9 * * *$ & $48.7 \pm 15.2$ \\
\hline VII & $\begin{array}{l}\text { Tramadol+ } \\
\text { Pregabalin }\end{array}$ & $4+6$ & $15.8 \pm 1.7 * * *$ & $55.5 \pm 6.6$ \\
\hline VIII & $\begin{array}{l}\text { Tramadol+ } \\
\text { Pregabalin }\end{array}$ & $8+12$ & $13.8 \pm 3.4 * * *$ & $61.5 \pm 8.3$ \\
\hline
\end{tabular}

Table 2: Effect of tramadol or pregabalin alone or in combination on tail immersion latency.

\begin{tabular}{|c|c|c|c|c|c|}
\hline \multirow[t]{2}{*}{ Group } & \multicolumn{3}{|c|}{ Tail Immersion Latency (sec) } & \multicolumn{2}{|l|}{$\% \mathrm{MPE}$} \\
\hline & 0 h $($ Mean \pm SD $)$ & 1 h $($ Mean \pm SD $)$ & 2 h $($ Mean \pm SD $)$ & 1 h $($ Mean \pm SD $)$ & 2 h $($ Mean \pm SD $)$ \\
\hline I & $4.9 \pm 0.2$ & $5.0 \pm 0.4$ & $5.1 \pm 0.6$ & $4.3 \pm 0.9$ & $4.9 \pm 0.7$ \\
\hline II & $4.9 \pm 0.5$ & $7.6 \pm 0.5 * * *$ & $7.8 \pm 0.5 * * *$ & $25.9 \pm 8.2$ & $28.7 \pm 5.5$ \\
\hline III & $5.3 \pm 0.5$ & $10.9 \pm 1.2 * * *$ & $11.7 \pm 1.1 * * *$ & $59.2 \pm 11.4$ & $60.8 \pm 11.2$ \\
\hline IV & $5.1 \pm 0.5$ & $11.2 \pm 1.0 * * *$ & $11.8 \pm 1.2 * * *$ & $65.8 \pm 11.2$ & $66.3 \pm 9.4$ \\
\hline $\mathrm{V}$ & $5.1 \pm 0.4$ & $6.9 \pm 0.5 * * *$ & $7.1 \pm 0.7 * * *$ & $17.8 \pm 6.2$ & $20.1 \pm 9.7$ \\
\hline VI & $5.0 \pm 0.3$ & $7.1 \pm 0.8 * * *$ & $7.3 \pm 0.5 * * *$ & $21.1 \pm 7.5$ & $23.1 \pm 5.5$ \\
\hline VII & $5.0 \pm 0.4$ & $10.3 \pm 0.9 * * *$ & $11.3 \pm 1.5^{* * *}$ & $53.3 \pm 8.7$ & $63.3 \pm 14.9$ \\
\hline VIII & $5.0 \pm 0.4$ & $11.9 \pm 0.9 * * *$ & $12.1 \pm 1.8 * * *$ & $69.2 \pm 9.3$ & $71.5 \pm 17.0$ \\
\hline
\end{tabular}

ANOVA $\mathrm{F}=73.94$

$* * * \mathrm{p}<0.001$ as compared to $0 \mathrm{~h}$

The highest percent inhibition was observed with the high dose combination group. Tukey HSD Post-hoc Test revealed that the combination was more effective than either low or high dose tramadol in the reduction of writhes. Administration of tramadol, pregabalin or tramadol plus pregabalin to conscious male Swiss mice 
caused dose and time-dependent antinociceptive effects in the tail immersion test, with different individual potencies (Table 2). The greatest antinociceptive response occurred with tramadol pregabalin combination after $2 \mathrm{~h}$ in the tail immersion test.

The results of the analgesic effect of the drugs using hot plate method are presented in Table 3. The results revealed that there was no significant difference on the thermal stimulus in rats treated with normal saline (control group) throughout the observation period. There was a statistically significant increase in reaction time at all time points compared to baseline values in all treatment groups and was greatest for combination treated group at $2 \mathrm{~h}$ after treatment. The experimentallyderived value of the maximum possible antinociceptive effect for low dose combination was $81.7 \pm 5.1 \%$ while at $1 \mathrm{~h}$ it was $92 \pm 8.5 \%$.

Table 3: Effect of tramadol or pregabalin alone or in combination on response latency in Hot Plate test.

\begin{tabular}{|c|c|c|c|c|c|}
\hline \multirow[t]{2}{*}{ Group } & \multicolumn{3}{|c|}{ Response Latency (sec) } & \multirow[b]{2}{*}{$11 / 2 h($ Mean \pm SD $)$} & \multirow[b]{2}{*}{2 h $($ Mean \pm SD $)$} \\
\hline & 0 h $($ Mean \pm SD $)$ & 1/2 h $($ Mean \pm SD $)$ & 1 h $($ Mean \pm SD $)$ & & \\
\hline I & $3.7 \pm 0.1$ & $3.9 \pm 0.3$ & $4.7 \pm 0.2$ & $4.6 \pm 0.2$ & $3.9 \pm 0.3$ \\
\hline II & $3.7 \pm 0.2$ & $11.7 \pm 4.0 * * *$ & $12.3 \pm 5.2 * * *$ & $9.7 \pm 2.2 * * *$ & $9.3 \pm 2.1 * * *$ \\
\hline III & $4.5 \pm 0.5$ & $13.1 \pm 0.9 * * *$ & $10.8 \pm 1.0 * * *$ & $9.3 \pm 0.9 * * *$ & $4.5 \pm 0.6^{* * *}$ \\
\hline IV & $4.5 \pm 0.6$ & $9.2 \pm 1.7 * * *$ & $11.7 \pm 0.7 * * *$ & $10.3 \pm 0.7 * * *$ & $7.5 \pm 1.2 * * *$ \\
\hline $\mathrm{V}$ & $4.4 \pm 0.5$ & $9.3 \pm 0.5 * * *$ & $12.9 \pm 0.7 * * *$ & $9.7 \pm 0.8 * * *$ & $7.5 \pm 0.3 * * *$ \\
\hline VI & $4.0 \pm 0.3$ & $9.3 \pm 0.4 * * *$ & $13.3 \pm 3.2 * * *$ & $9.9 \pm 0.6 * * *$ & $8.5 \pm 1.6^{* * *}$ \\
\hline VII & $3.3 \pm 0.8$ & $15.3 \pm 2.6 * * *$ & $16.9 \pm 0.9 * * *$ & $11.7 \pm 1.1 * * *$ & $9.7 \pm 0.6 * * *$ \\
\hline VIII & $3.6 \pm 0.2$ & $14.0 \pm 0.7 * * *$ & $18.7 \pm 0.8 * * *$ & $15.0 \pm 0.9 * * *$ & $12.0 \pm 0.2 * * *$ \\
\hline
\end{tabular}

ANOVA F $=45.9$

$* * * \mathrm{p}<0.001$ as compared to $0 \mathrm{~h}$

Table 4: Effect of tramadol or pregabalin alone or in combination on carrageenan-induced paw oedema in mice.

\begin{tabular}{|lllll|}
\hline \multirow{2}{*}{ Group } & \multicolumn{2}{l}{ Paw volume $(\mathbf{m L})(\mathrm{Mean} \pm \mathrm{SD})$} \\
\cline { 2 - 4 } & Before carrageenan & $\mathbf{2 . 5} \mathbf{~ h}$ after carrageenan & $\mathbf{1}$ h after (test drug) & 2 h after (test drug) \\
\hline I & $1.35 \pm 0.03$ & $2.56 \pm 0.06$ & $2.52 \pm 0.06$ & $2.54 \pm 0.06$ \\
\hline II & $1.35 \pm 0.03$ & $2.59 \pm 0.04$ & $1.98 \pm 0.08 * *$ & $1.86 \pm 0.07 * *$ \\
\hline III & $1.35 \pm 0.04$ & $2.54 \pm 0.12$ & $2.52 \pm 0.12$ & $2.51 \pm 0.10$ \\
\hline IV & $1.34 \pm 0.02$ & $2.54 \pm 0.09$ & $2.49 \pm 0.06$ & $2.48 \pm 0.08$ \\
\hline V & $1.35 \pm 0.03$ & $2.49 \pm 0.06$ & $2.47 \pm 0.12$ & $2.43 \pm 0.07$ \\
\hline VI & $1.35 \pm 0.02$ & $2.57 \pm 0.10$ & $2.52 \pm 0.04$ & $2.52 \pm 0.09$ \\
\hline VII & $1.35 \pm 0.02$ & $2.61 \pm 0.08$ & $2.58 \pm 0.03$ & $2.53 \pm 0.07$ \\
\hline VIII & $1.35 \pm 0.04$ & $2.48 \pm 0.06$ & $2.43 \pm 0.02$ & $2.39 \pm 0.11$ \\
\hline
\end{tabular}

ANOVA F $=353.45$

** $\mathrm{P}<0.01$ as compared to $0 \mathrm{~h}$ value

The results of $\lambda$-carrageenan-induced mice paw oedema (Table 4) indicated that diclofenac alone significantly inhibited the development of paw oedema induced by carrageenan after 1 and $2 \mathrm{~h}$ of treatment. Neither tramadol nor pregabalin alone or in combination, exhibited negligible anti-inflammatory activity in Carrageenan induced hind paw oedema.

\section{DISCUSSION}

The present study carried out to evaluate the analgesic and anti-inflammatory activity of tramadol and pregabalin when used alone or in combination demonstrated an antinociceptive activity, independent of the animal models of nociception or the nociceptive stimulus in a dose dependent manner without significant anti-inflammatory activity. The addition of a second agent in multimodal analgesia, which may or not also be an analgesic, may prolong analgesic duration, enhance analgesic efficacy, diminish or minimize adverse effects and could reduce opioid tolerance or dependence. ${ }^{21}$ Since pregabalin has been shown to enhance the analgesic activity of tramadol, this combination may be clinically efficacious in conditions associated with acute pain.

Nociceptive information is processed and integrated peripherally as well as at spinal and supraspinal level within the central nervous system. In the present study, 
we found that the combination of tramadol and pregabalin elicited an antinociceptive action in chemical and thermal models of pain in mice and rats. Our results indicate that the combination was effective in inhibiting thermal nociception at different levels of the central nervous system, as the hot-plate test predominantly measures supraspinal response to a stimulus while the tail-flick test primarily measures the spinal response to a stimulus. ${ }^{22}$ The present data also suggests that the combination might have peripheral effects on the modulation of acute nociceptive stimuli since acetic acid induced writhing was also significantly inhibited. Taken together, the data suggest that the combination appears to be a good candidate for multimodal coverage of a wider spectrum of pain.

Perusal of the doses used in this study indicate that we can achieve the same antinociceptive effect by reducing the dose of tramadol in combination therapy. Thus, the reduction of tramadol dose during the treatment with these drugs may contribute to the limitation of the acute adverse effects exerted by tramadol when used alone at high doses. The decrease in the doses of tramadol may enhance tolerability and patient compliance in chronic pain states. Our study hints that the combination of tramadol and pregabalin may satisfy the criteria for multimodal analgesia. Since combination analgesics offer the possibility of efficient analgesia with a decrease in side effects as a result of reduced dosages of one or both compounds, this combination appears to be a good candidate for acute pain. ${ }^{23}$

The available evidence for additive or synergistic effects of most combination regimens is sparse, and our knowledge and understanding of these combinations is limited. ${ }^{24}$ The strength of the present study is that it provides scientific evidence on a range of different acute pain models in animals. Since the interaction of a combination depends not only on the different mechanisms of drug action, but also on the relative amounts of the drugs in the combination tested, isobolographic analysis and interaction index studies are warranted to delineate whether the combination of tramadol and pregabalin is additive, supra additive or synergistic.

\section{CONCLUSION}

From this study, we can conclude that that tramadol pregabalin combination is more efficacious than tramadol or pregabalin alone in acute animal models of pain. Nevertheless, our hypothesis should be confirmed in additional models of acute and/or chronic pain and if confirmed, the combination might be useful in the management of pain not associated with peripheral inflammation particularly among the elderly population at heightened risk for the adverse renal and gastrointestinal effects of NSAIDs.
Funding: No funding sources

Conflict of interest: None declared

Ethical approval: The study was approved by the Institutional Scientific Research and Animal Ethics Committee

\section{REFERENCES}

1. Rocha AP, Kraychete DC, Lemonica L, de Carvalho LR, de Barros GA, Garcia JB, et al. Pain: current aspects on peripheral and central sensitization. Rev Bras Anestesiol. 2007 Feb;57(1):94-105.

2. Woolf CJ. Central sensitization: implications for the diagnosis and treatment of pain. 2011 Mar;152(3):S215.

3. Latremoliere A, Woolf CJ. Central sensitization: a generator of pain hypersensitivity by central neural plasticity. J Pain. 2009 Sep;10(9):895-926.

4. Derry S, Wiffen PJ, Moore RA. Relative efficacy of oral analgesics after third molar extraction: a 2011 update. Br Dent J. 2011 Nov 11; 211(9):419-20.

5. Bauer CS, Nieto-Rostro M, Rahman W, Tran-VanMinh A, Ferron L, Douglas L, et al. The increased trafficking of the calcium channel subunit alpha2delta-1 to presynaptic terminals in neuropathic pain is inhibited by the alpha2delta ligand pregabalin. J Neurosci. 2009 Apr 1;29(13):4076-88.

6. Stahl SM, Porreca F, Taylor CP, Cheung R, Thorpe AJ, Clair A. The diverse therapeutic actions of pregabalin: is a single mechanism responsible for several pharmacological activities? Trends Pharmacol Sci. 2013 Jun;34(6):332-9.

7. Zhang J, Ho KY, Wang Y. Efficacy of pregabalin in acute postoperative pain: a meta-analysis. $\mathrm{Br} \mathrm{J}$ Anaesth. 2011 Apr;106(4):454-62.

8. Frampton JE, Foster RH. Pregabalin: in the treatment of postherpetic neuralgia. Drugs. 2005;65(1):111-8.

9. Mishriky BM, Waldron NH, Habib AS. Impact of pregabalin on acute and persistent postoperative pain: a systematic review and meta-analysis. Br J Anaesth. 2015 Jan;114(1):10-31.

10. Scott LJ, Perry CM. Tramadol: a review of its use in perioperative pain. Drugs. 2000;60:139-76.

11. Dhillon S. Tramadol/paracetamol fixed-dose combination: a review of its use in the management of moderate to severe pain. Clin Drug Investig. 2010;30(10):711-38.

12. Pergolizzi JV, van de Laar M, Langford R, Mellinghoff HU, Merchante IM, Nalamachu S, et al. Tramadol/paracetamol fixed-dose combination in the treatment of moderate to severe pain. J Pain Res. 2012;5:327-46.

13. Tripathi S, Shah R, Sharma DC. Analgesic activity of fixed dose combinations of paracetamol with diclofenac sodium and paracetamol with tramadol on different pain models in healthy volunteers: A randomized double blind crossover study. J Anaesthesiol Clin Pharmacol. 2012 Oct;28(4):465-9.

14. Suthakaran C, Kayalvizhi MK, Nithya K, Raja TAR. Evaluation of analgesic and anti-inflammatory 
tramadol-ibuprofen in experimental animals. Ind $\mathrm{J}$ Dental Res. 2017;28:(In Press).

15. Koster R, Anderson M, de Beer EJ. Acetic acid for analgesic screening. Fed Proc. 1959;18:412.

16. Luttinger D. Determination of antinociceptive efficacy of drugs in mice using different water temperatures in a tail-immersion test. J Pharmacol Methods. 1985 Jul;13(4):351-7.

17. Pinardi G, Sierralta F, Miranda HF. Atropine reverses the antinociception of nonsteroidal anti-inflammatory drugs in the tail-flick test of mice. Pharmacol Biochem Behav. 2003 Feb;74(3):603-8.

18. Eddy NB, Leimbach D. Synthetic analgesics. II. Dithienylbutenyl- and dithienylbutyl amines. J Pharmacol Exp Ther. 1953 Mar;107(3):385-93.

19. Winter CA, Risley EA, Nuss GW. Carrageenaninduced oedema in hind paw of the rat as an assay for anti-inflammatory drugs. Proc Soc Exp Biol Med. 1962 Dec;111:544-7.

20. Singh H, Ghosh MN. Modified plethysmometer for measuring foot volume of unanesthetized rats. J Pharm Pharmacol. 1968 Apr;20(4):316-7.

21. Smith HS. Combination opioid analgesics. Pain Physician. 2008 Mar-Apr;11(2):201-14.
22. Langerman L, Zakowski MI, Piskoun B, Grant GJ. Hot plate versus tail flick: evaluation of acute tolerance to continuous morphine infusion in the rat model. J Pharmacol Toxicol Methods. 1995 Sep;34(1):23-7.

23. Raffa RB. Pharmacology of oral combination analgesics: rational therapy for pain. J Clin Pharm Ther. 2001 Aug;26(4):257-64.

24. Dahl JB, Nielsen RV, Wetterslev J, Nikolajsen L, Hamunen K, Kontinen VK et al. Post-operative analgesic effects of paracetamol, NSAIDs, glucocorticoids, gabapentinoids and their combinations: a topical review. Acta Anaesthesiol Scand. 2014 Nov;58(10):1165-81.

Cite this article as: Suthakaran C, Raja TAR, Kayalvizhi MK, Nithya K, Reddy RRV. Evaluation of analgesic and anti-inflammatory activity of a combination of tramadol-pregabalin in animal models of pain and inflammation. Int $\mathbf{J}$ Basic Clin Pharmacol 2017;6:1511-6. 